\title{
Profound anaemia in an elderly man
}

\author{
DG Swain
}

A 74-year-old man presented with pallor in March 1993. He had no gastrointestinal symptoms, haematemesis or melaena. He had received a nasal boxing injury aged 12 , since when he had suffered small self-limiting epistaxes twice a week. There was no family history of bleeding. He had had ankle swelling for nine months, but no other cardiac symptoms.

On examination he was very pale and wasted. There were a few lingual telangiectases. The pulse was 80 beats/min and irregular. The blood pressure was $140 / 40 \mathrm{mmHg}$ with no postural fall. The jugular venous pressure was elevated $6 \mathrm{~cm}$, there was oedema to mid-thigh level, but there were no chest signs. The heart sounds were normal, apart from a soft apical systolic flow murmur. He had mild cognitive impairment, the knee and ankle reflexes were absent, and sensation was impaired in all modalities below the knees.

Initial investigations showed haemoglobin $2.1 \mathrm{~g} / \mathrm{dl}$, mean corpuscular volume $53.8 \mathrm{fl}$, white cell count $4.2 \times 10^{9} / 1$, platelets $235 \times 10^{9} / 1$ and reticulocytes $3.8 \%$. The Direct Coombs test and red cell antibody screen were negative. Iron deficiency was confirmed with ferritin $6 \mu \mathrm{g} / 1$ (reference range $30-300)$, iron $<2 \mu \mathrm{mol} / 1(14-29)$ and iron binding capacity $76 \mu \mathrm{mol} / 1$ (4572).

He was transfused with one unit of concentrated red cells daily for seven days. After three units, the heart failure had completely resolved and further multiple telangiectases of the earlobes, nose, face, tongue and palate were noted (figure).

Department of Geriatric Medicine, Arden Lodge Annex, Yardley Green Hospital, Birmingham Heartlands NHS Trust, Birmingham B5 9PX, UK DG Swain

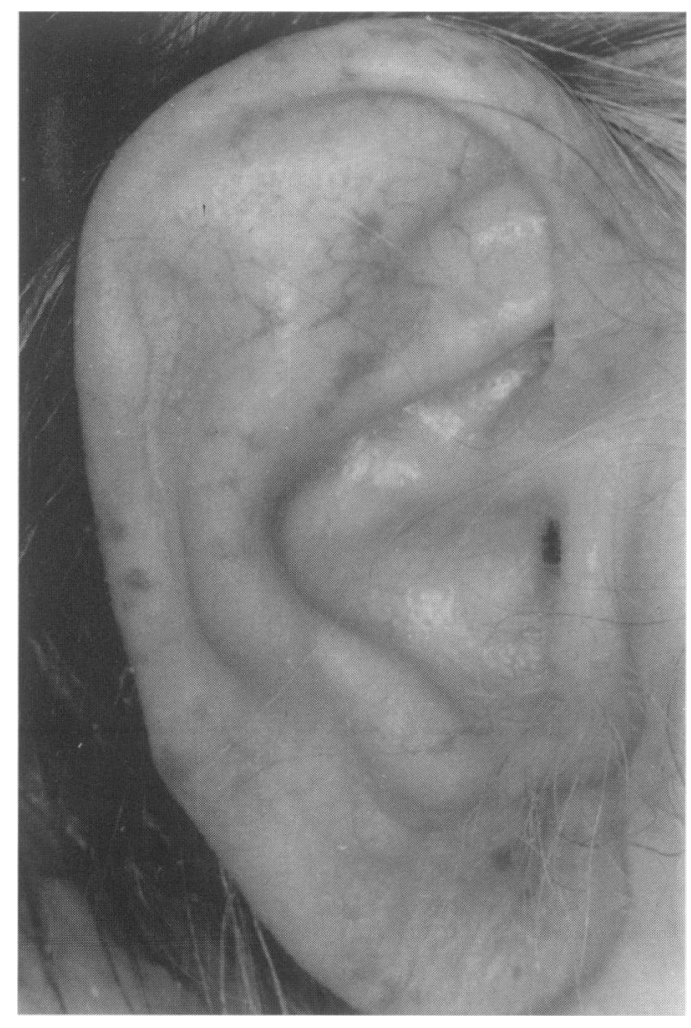

\section{Questions}

1 What is the most likely cause of the anaemia?

2 What other diagnoses should be considered?

Figure Earlobe telangiectases 
Answers

QUESTION 1

Hereditary haemorrhagic telangiectasia (HHT). Endoscopy showed telangiectatic lesions in the mouth, pharynx, oesophagus, stomach and duodenum. Colonoscopy revealed extensive telangiectases throughout the whole colon. The cutaneous telangiectases were not visible initially due to the profound anaemia, but became so with partial correction of the anaemia.

QUESTION 2

Other diagnoses which should be considered are local nasal, and gastrointestinal causes of bleeding and haematinic deficiency.

An ear, nose and throat assessment revealed nasal telangiectases, nasal septal deviation to the right and two bleeding points in Little's area on the left. In addition there was a large blood vessel in the left anterior nares not related to any telangiectatic lesion, which bled actively when disturbed. The bleeding points were cauterised with silver nitrate and naseptin cream applied.

Endoscopy also showed a $1 \mathrm{~cm}$ diameter ulcer in the gastric fundus, biopsies of which showed gastritis with Helicobacter-like organisms. The patient received denol, metronidazole and amoxycillin. Vitamin B12 levels were normal but serum folate was rather low at $2.4 \mu \mathrm{g} / 1(2.2-12.6)$, which in the context of impaired cognition, wasting and peripheral neuropathy suggested folate deficiency. He received folic acid.

\section{Progress}

In August 1993, the patient's haemoglobin was $6.3 \mathrm{~g} / \mathrm{dl}$. He was transfused six units of concentrated red cells. Endoscopy showed multiple telangiectatic lesions with some active bleeding which settled spontaneously: the gastric ulcer had healed. During that admission, he had a large epistaxis due to bleeding from multiple vessels on the left nasal septum. This was successfully treated with silver nitrate cautery and naseptin cream. He was commenced on life-long ferrous sulphate $200 \mathrm{mg}$ tid, and has since maintained a normal haemoglobin in spite of the occasional small epistaxes.

1 Plauchu H, de Chadarévian J-P, Bideau A, Robert J-M. Ag related clinical profile of hereditary hemorrhagic telangiec tasia in an epidemiologically recruited population. Am Med Genet 1989; 32: 291 -

2 Reilly PJ, Nostrant TT. Clinical manifestations of hereditary hemorrhagic telangiectasia. Am $\mathcal{f}$ Gastroenterol 1984; 79, 363-7.

3 Smith CR, Bartholomew LG, Cain JC. Hereditary hemorrhagic telangiectasia and gastrointestinal hemorrhage. Gastroenterology 1963; 44: $1-6$.
Learning points

- epistaxis is rarely the sole cause of a profound anaemia. When the haemoglobin is less than $6 \mathrm{~g} / \mathrm{dl}$, another cause for the anaemia is almost certainly present

- epistaxis may result from a number of different nasal lesions

- patients with HHT may have nontelangiectatic causes of iron deficiency anaemia

\section{Discussion}

$\mathrm{HHT}$ is an autosomal dominant disorder of vascular proliferation characterised by epistaxes $(96 \%)$, mucocutaneous telangiectases (74-96\%) and gastrointestinal bleeding (15\%). ${ }^{1-3}$ Most patients (90\%) have become symptomatic with epistaxes by the age of $40 .^{1-3}$

The severity of anaemia in HHT has not been studied directly but may be inferred on the basis of lifetime transfusion requirements. In 159 patients with $\mathrm{HHT}$, blood transfusion was necessary in $63(40 \%) ; 21$ (13\%) patients had gastrointestinal bleeding, of whom 19 $(90 \%)$ needed transfusions and $10(50 \%)$ more than 30 transfusions. $^{3}$ In another study of 64 patients with HHT, $46 \%$ needed a blood transfusion. ${ }^{2}$

Profound anaemia is an unusual consequence of epistaxis. In a series of 1724 patients with epistaxis, ${ }^{4}$ the lowest recorded haemoglobin was less than $10 \mathrm{~g} / \mathrm{dl}$ in $31.6 \%$, but less than $6 \mathrm{~g} / \mathrm{dl}$ in only $1 \%$. In 340 patients with epistaxis, blood transfusion was needed in $10.3 \%$ but only $0.9 \%$ needed more than $800 \mathrm{ml}$ of blood. ${ }^{5}$

Duodenal ulceration is a well recognised association of $\mathrm{HHT}^{2,3}$ In addition, patients with HHT may have other gastrointestinal lesions, in common with the rest of the population.

\section{Final diagnosis}

Hereditary haemorrhagic telangiectasia.

Keywords: anaemia, epistaxis, elderly, hereditary haemorrhagic telangiectasia

4 Juselius H. Epistaxis: a clinical study of 1724 patients. $f$ Laryngol Otol 1974; 88: 317-27.

5 Moñux A, Tomás M, Kaiser C, Gavilán J. Conservative management of epistaxis. $\mathcal{F}$ Laryngol Otol 1990; 104: 86870 . 